\title{
Financial Information Project: message for the NHS
}

\author{
C A GREENHALGH，J N TODD
}

Many consultants believe that the cost of the services that they provide is not their concern. There are, however, an increasing number who accept that they do have a responsibility in the financial management of their unit and who appreciate that if they do not shoulder this particular burden someone else will. The National Health Service can no longer expect growth at the level of the past two decades and all concerned need to ensure that resources are used efficiently. Unfortunately, effective financial management of clinical units requires information on cost that is currently not available.

It is possible to identify the cost of some elements of the service, and this is more accurate when the clinical unit or specialty works from a clearly defined ward or group of wards. Even so, some costs-use of operating theatres, outpatients, drugs, laboratory and $x$ ray services-can only be estimated. This does not give confidence to those who are increasingly expected to take part in financial planning.

Current advice from the Department of Health and Social Security is that costs should be apportioned to specialties, and this is being done, but this still means estimating the cost of many items. ${ }^{1}$ It is, therefore, of little help to the individual clinician, assuming as it does that costs are equal between patients in the same specialty. The even more recent trend towards costing diagnostically related groups of patients is perhaps a step in the right direction. ${ }^{2}$ But the assumption that those in the same diagnostic group consume the same amount of health care resources implies that patients are treated (and therefore resources consumed) according to their diagnosis, regardless of the individual clinical characteristics or treatment. This may be a reasonable assumption for decisions in longer term plans, but in the short term, and in decision making relating to small units, wards, or groups of patients, averaging out is insensitive. So what is it that clinicians need in their role as managers rather than as users of resources? Information that is pertinent to style of work, treatment procedures, facilities, and resources-not standards, norms, national averages, and the like.

A different approach has been suggested by research carried out by the Financial Information Project. The project was set up in 1979 with a specific brief to examine the need for financial information for health care planning and for clinicians in the management and organisation of their units. The initial research showed that the only system capable of providing information to meet the needs expressed by different disciplines and management tiers would mean costing individual patient episodes of care. Specialty costs were noted as a considerable improvement for longer term planning decisions, but for short term decisions at unit, hospital, and ward level the service needs cost data related to location, diagnosis, treatment, consultant, time period, age group, etc. The only means of obtaining all of these

Financial Information Project, Birmingham B1 2JP

C A GREENHALGH, principal project officer

Sheffield Health Authority, Sheffield S11 8EU

J N Todd, MB, MFCM, district medical officer

Correspondence to: Mrs Greenhalgh, Financial Information Project, 11 th Floor, Alpha Tower, Suffolk Street, Queensway, Birmingham B1 2JP. simultaneously is to cost at the level of the individual patient. This seemed almost impossible, however, except at prohibitive expense, so studies were set up in two centres to determine the detail needed and the implications of obtaining it.

\section{Costing individual patients}

The second phase of research, therefore, attempted to answer the question, "Is it practicable and feasible in the hospital and in the community to cost individual patients ?" Many people had faith in the principle but were sceptical about the practice.

The project chose a few wards in a large modern district general hospital in Coventry and investigated four major specialties-general surgery, neurology, neurosurgery, and geriatric medicine-and costed all resources used by these patients. This led to work in 26 different resource areas. In the community the project looked at several services in south Birmingham used mainly by the elderly-home nursing, geriatric health visiting, domiciliary incontinence service, and loan of equipment service.

In both settings we found that accurate patient costing required identification of the activity that consumed resources in terms of staff time and use of consumables. These were recorded, costed, and linked to individual patient attributes by means of a unique patient number. In this way, not only were individual patient cost data possible and feasible but valuable data for the effective management of that activity were also provided.

The need for useful activity measures has been apparent from the difficulty found in choosing a suitable measure for nursing activity. National initiatives have had to settle for what has been readily available-numbers of beds, discharges, inpatient days-but subsequent research has provided greater precision. In the past nursing resources have been distributed by inpatient day, on the assumption that all patients in all specialties incur an equal cost per day. Recent moves towards specialty costing provide for a specific cost per inpatient day for a specialty, identifying actual expenditure by specialty. Work also continues on diagnostic related groupings. Diagnostic grouping and specialty costing, however, both assume that the consumption of resources is the same for all patients in the specialty and diagnostically related group and indeed remains the same throughout a patient's length of stay. The project's approach was to develop work done on dependency grouping of patients-measured by their need for nursing time-by reference to specific factors that influence the nursing time required on a daily basis. This activity based system may then be used to provide a means of disaggregating ward costs to consultant, specialty, age, sex, diagnosis, etc. Specific and useful

Variation in the total cost (staff and consumables)* per operation type

\begin{tabular}{lccc}
\hline & No in sample & $\begin{array}{c}\text { Mean } \\
(£)\end{array}$ & $\begin{array}{c}\text { Standard deviation } \\
(£)\end{array}$ \\
\hline Total cholycystectomy & 27 & 103.14 & 33.788 \\
Varicose veins (stripping) & 33 & 77.08 & 31.061 \\
Partial thyroidectomy & 20 & 111.86 & 34.731 \\
\hline
\end{tabular}

*Extract from final report of Financial Information Project.“ 
activity measures were identified and adopted in all the project's systems.

In the area of medical staff activity, where little previous research has been done, the project attempted to relate medical staff time to individual patients by applying the principle of a standard profile, a curve based on length of stay (assuming a reducing input of medical staff time until day of discharge), and adjusting this for individual patients according to diagnosis, major procedures carried out, and any complications. Data collected as part of the discharge summary provided information on the differential use of medical staff time throughout a patient's stay. Used in an aggregate form, the data could provide indicators of total medical workload over a time period.

This part of the study could not proceed beyond the preliminary stage of identifying a possible approach; continuation of the work would need to consider the potential use of such data. At some time it may be appropriate to continue this early work, relating systems more closely to the operational management of medical staffing services. In the short term, however, greater immediate benefit is likely to be gained from pursuing patient activity systems in other resource areas.

\section{Measuring other activities}

The project determined the appropriate activity measure in many other resource areas, using a weighted or actual cost, and linked this to patients through the use of the individual patient number, thereby linking the use of resources to individual patient attributes collected on admission. In some resource areas the project developed detailed operational systems to collect this data-for instance, in theatres, ward nursing, and home nursing. In others only the potential approaches were identified and pilot studies done in the time available.

At the end of the second phase of research the project addressed the initial question of whether patient costing was worth doing in its own right. Did patients differ sufficiently from each other to warrant such detailed systems purely to provide patient costs? Considerable research elsewhere has established that patients do differ in total cost between specialties, and work is continuing into ways of grouping patients by diagnosis. ${ }^{3}$ But the initial work in Coventry, although limited to only four specialties, pointed to marked differences in use of resources per day between patients with exactly the same diagnosis and between patients requiring the same treatment procedure. An example of the differences between the theatre costs of individual patients having the same operation is given in the table.

Within the pilot study there were too few operations of the same type to provide greater analyses or to formulate conclusions, but all operations (with the exception of circumcisions) carried out on more than 10 patients showed a substantial variation in total cost. Differences between actual costs and average costs were found between patients of the same specialty in most of the 26 resource areas examined, including all the diagnostic and remedial services under review. This preliminary research pointed to the potential problems in using average costs by specialty by showing differences between patients of the same specialty in respect of location, consultant, and diagnostic distribution.

During the course of our work we realised that the activity systems being developed for patient costing were useful not just for this purpose: in most resource areas they also produced data of value for effective management by providing a means of deploying staff. Patient based activity systems provide more than the cost of a patient-a whole range of data for management becomes available.

It was clear that any systems developed should be of operational use and be an integral part of the delivery of service, so avoiding the need for numerous information systems that generated unnecessary extra work. In many resource areas considerable individual patient data were already being collected, in notebooks, diaries, and loose leaf folders, quite often in informal systems devised by local staff. None of these data were being aggregated or analysed, largely because of lack of facilities, although many of them clearly could have provided a wealth of information if adequate computer facilities had been available. Such arrangements are probably normal rather than the exception. When the project started we envisaged using manual systems where feasible, but the increasing availability of computers and their obvious advantage led us to switch to using computerised systems.

Where does this work fit in with other NHS management initiatives?

The sixth report of the Steering Group on Health Services Information recommended that specialty costing should be introduced and suggested that patient based costing was the "most difficult to develop." 1 The Financial Information Project would agree, if costing were the only reason for developing and introducing systems. The project's systems are provided essentially for operational management and planning and in providing data for this purpose may also provide data to analyse expenditure. Other initiatives in clinical and management budgeting are being introduced and tested in second generation sites in several places. These have concentrated on obtaining a greater sensitivity in apportioning costs to location, to budget holders, and to budget users, and include activity measures to be used in conjunction with costs. The project is concerned with providing the most useful activity data for this purpose, but not exclusively so. Our research has shown that, though a single activity measure may be useful enough as a broad indicator of changing workload for some purposes, these measures are of little practical use unless they can be identified by exact type of activity and unless costs and workload can be attributed to patients of common specialty, location, diagnosis, treatment type, clinician, age group, etc.

The second phase of the project is now under way in a district developing a detailed management budgeting system. We intend to use the project's patient based data to feed into this system for specialty and clinical costing and to provide activity related budget reports. At the same time we hope to provide the data necessary to answer the question, "Why has this happened ?" which is inevitably raised when such data are produced.

The Financial Information Project is continuing its work, developing individual operational packaged computer activity and cost systems in several different resource areas. These will be made available as discrete modules to any interested districts as they are completed. They will link at the individual patient level, which will allow an incremental approach to a total patient costing to be adopted. This in turn will permit priorities for implementation to be determined by individual districts according to local circumstances. Useful data are, therefore, available immediately for management and planning of individual resource areas, while in the long term each module in the total system can eventually be put together to provide a total costing system. It will then be possible to answer questions relating to decisions about cost of different treatments or procedures, cost of changes in technology, epidemiological changes, and demographic changes, as well as costs of services under the direct control of those who work in the NHS.

Detailed results of the work carried out to date by the project are available in a series of reports and can be supplied on request.

\section{References}

1 Steering Group on Health Services Information. Sixth report. Health services finance. London: HMSO, 1984:15.

finance. Lring Social Service fournal 1984 ; July $26: 884-5$.
Sypins

3 Magee CC, Osmolski RJ. A comprehensive system of management information for financial planning, decision making and control in the hospital service. Technical paper for Royal Commission on the NHS. University of Warwick: Centre for Economic and Business Research, 1978.

4 Financial Information Project. Patient based costing in the hospital. Birmingham: Financial Information Project, 1984:123-31.

(Accepted 28 December 1984) 


\section{Reducing juniors' hours of work}

In negotiations with the Department of Health and Social Security the BMA has gradually achieved reductions in the hours of work of junior hospital doctors. In 1983 regular rota commitments more onerous than one in two were prohibited and health authorities were asked to ensure that only in exceptional circumstances should doctors be able to contract as internal locums if this meant that their total commitment would be more onerous than one in two. The proportion of junior doctors on rotas more onerous than one in three has gradually been reduced and these have been reviewed regularly by regional panels.

The DHSS has now issued a circular on arrangements designed to minimise the occasions when a junior doctor who has a regular rota commitment more onerous than one in three, particularly one who is hard pressed, would be required to cover for an absent colleague and be on duty more often than one night and one weekend in two on average.

This would be achieved by having regular rota commitments, which are one in three or less onerous. District working parties, which were established to review on call rota commitments, should now be asked to examine all remaining rotas more onerous than one in three in order to ensure that arrangements for taking annual and study leave are satisfactory; to review the arrangements for providing cover when one of the doctors on the rota is absent, other than in an emergency; and to consider arrangements which should be made if a doctor is required to be on duty more often than one in two when covering for an sbsent colleague, other than in an emergency.

The circular sets out the arrangements that should be followed for dealing with posts where the burden of call out is likely to be heavy, for time off, and for additional leave.

1 Department of Health and Social Security. Pay and conditions of service. Funior hospital medical and dental staff: hours of work. London: DHSS, 1985. (PM (85)1.)

\section{BMA's concern at pension taxation rumours}

Rumours about the possibility of the taxation of lump sum retiring allowances and of pension funds on their investment income have prompted the chairman of the BMA's superannuation committee to obtain the council's support for a letter to Mr Norman Fowler, asking him to draw the matters to the attention of the Chancellor of the Exchequer.

In an appendix to his letter to the Secretary of State for Social Services Dr B L Alexander said that the possibility of taxing limp sum retiring allowances would be damaging and divisive. Like other public sector schemes the National Health Service. superannuation scheme was a compulsory commutation scheme and there was no option but to take a lump sum. This had long been regarded as an amount in lieu of pension. "The occupational pension scheme rights of those engaged in work in the public sector, whether it be in the NHS, the Civil Service, the armed forces, or other

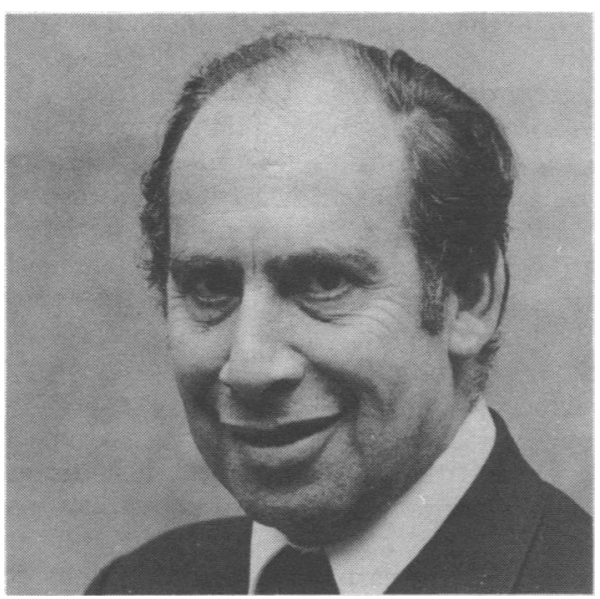

Dr B L Alexander.

similar employments, have long been recognised as an implied contract term in respect of which expectations the salary levels over the years have been artificially depressed."

Dr Alexander said that the second threatthat the investment income and capital gains of pension funds might be subject to taxwas potentially more damaging. Warning that such a change could lead to the virtual destruction of occupational pension schemes, he said that the imposition of even standard rate tax on investment income would probably ensure that the rate of return on investments would be less than the rate of pay inflation.

\section{BMA president appeals to EEC on limited list}

The president of the BMA, Sir Douglas Black, has written to the president of the European Commission to ask him "as a matter of urgency" to intervene to prevent the government from going ahead with its scheme to make National Health Service patients pay for certain drugs. The BMA believes that the scheme contravenes European law.

In his letter Sir Douglas said:

"On consulting solicitors the association's attention was drawn to the decision of the European Court of Justice in the case of Duphar and others against the Netherlands ... and we were advised that if the proposed list was not to infringe European law then, in the light of that decision, the list must not be discriminatory concerning the origin of products, must be carried out on the basis of objective and verifiable criteria, and must be capable of amendment whenever compliance with the specified criteria so require.

"Consequent on this advice our solicitors wrote to the Minister of Health (who represents the Secretary of State in this matter) and inquired what the objective criteria might be and how he proposed that they should be verified. Here I might explain incidentally that there is already a well established procedure under the health service scheme for deciding whether or not a new product is indeed a 'drug' and so prescribable under the scheme. We envisaged that similar detailed arrangements would be needed to prepare the present list.

"Despite the minister having time for consideration, and our attending on him some 12 days after the solicitors' inquiry, no answer to the request has been forthcoming and we continue to have severe doubts about whether or not there are objective criteria for inclusion on the list, and, if indeed there are any, whether they are verifiable as required by the Court of Justice.

"In addition to the Duphar case our solicitors have also drawn our attention to the views of the commission on similar issues. In particular, we understand that the Italian and German governments have modified similar lists following representations being made by the commission, and that the commission is presently dealing with a similar problem involving the Greek government.

"In the circumstances I am writing on behalf of the association to request the assistance of the commission in preventing the United Kingdom from breaching Community law and would invite the commission to take urgent action under Articles 90 and 169 of the Treaty. Our solicitors have particularly directed our attention to Treaty Articles 5, 7, 30, 31, and 37 which in their opinion would be contravened by the present proposals, and in view of the proposed commencement date of 1 April we would ask that the commission intervene as a matter of considerable urgency."

\section{Directory of general practitioner hospitals}

Ideally, says the Association of General Practitioner Hospitals, there should be between 1000 and 1500 general practitioner hospitals in Britain, but there are just over 400 . The fact that this number has been maintained is due in large part to the efforts of that association, a pressure group founded in 1969 when these small hospitals were under threat. The 1962 hospital plan aimed to close them, but there was never sufficient money to do so. For the first time all the cottage hospitals in England and Wales (the Scottish association has been active since 1981) that admitted patients under the care of their general practitioner were identified. Since then the association has been the only source of advice and support for doctors and patients wanting to preserve and expand general practitioner hospitals.

On 24 January the association's president, Dr $R$ M Emrys-Roberts, and its chairman, Dr A J M Cavenagh, launched the first handbook and directory. It brings together details of all the general practitioner hospitals in Great Britain, providing workload comparisons, helping communication between hospitals sharing common problems, and containing sections on acute medicine, nursing services, the payment of general practitioners, community hospitals in inner cities, and advice on preventing closure. It was reported that 20 projects were under discussion in the West Midlands and that the first purpose built urban general practitioner hospital would open in west Lambeth this year, with 20 beds, 35 day places, and participation by 20 general practitioners.

The handbook may be obtained from Dr Cavenagh, Ruperra House, St Mary Street, Brecon, Powys LD3 7AA, price $£ 4.50$, but free to members of his association. 